- This paper is the first to present the actual NHS and independently funded working hours of dentists in general or community practice in Scotland in 2000, as reported by the respondents to a questionnaire survey.

- The findings should allow manpower planners to focus on the reasons for loss of dentists and to consider ways of encouraging them to remain in dentistry for longer.

- Comparisons of GDPs and CDPs provide beneficial insights for workforce and career planning.

- This paper also complements the recent qualitative report of women dentists' concerns.

\title{
Dentists in general and community practice: a Scottish survey
}

\author{
E. Russell ${ }^{1}$ and M. Leggate ${ }^{2}$
}

\begin{abstract}
Objectives To identify the available workforce in general dental practice and to describe the job satisfaction, career and retirement plans of dentists in general and community practice.

Design A postal cross-sectional survey.

Setting Primary care dentists practising in Scotland in 2000.

Materials and methods Semi-structured questionnaires were sent to all primary care dentists identified from the Scottish Dental Practice Division as being in practice in Scotland.

Results The response rate was 70\% (1,335 GDPs and 187 CDPs). Although most dentists in both the GDS and CDS stated that they enjoyed their work, 35\% of GDPs would not now choose dentistry as a career. Eighty-three per cent of the GDPs' time was spent on clinical work, of which $5 \%$ was not NHS-funded. Daily demotivation was reported by $70 \%$, most commonly citing the job itself and the NHS 'treadmill'. Two-thirds of CDPs were women, as were half of GDPs aged less than 30 . Only $35 \%$ of CDPs planned early retirement but $80 \%$ of them felt underused. Two-thirds of GDPs planned to retire in their mid$50 \mathrm{~s}$, and a further quarter planned to work part-time. Of the former, only a quarter agreed that nothing would induce them to work beyond this time.

Conclusion Conditions of work within primary care dentistry require modification to retain the current workforce and accommodate the increasing proportion of women. Part-time employment packages may encourage older practitioners to work for longer, and allow younger practitioners to fulfil family or personal commitments.
\end{abstract}

Little is known about the working patterns and total workforce characteristics of general dental practitioners (GDPs) and community dental practitioners (CDPs) in Scotland. The Dental Practice Division (DPD) of the Information Services Division (ISD) of the Common Services Agency in Scotland records only the total number of dentists working in different grades across the country. Thus while it is known that the numbers of dentists employed in general dental

${ }^{1 *}$ Elizabeth Russell, Department of Public Health, University of Aberdeen; ${ }^{2}$ Margaret Leggate, Continuing Professional Development Tutor for General Dental Practice, Dental Postgraduate Advisers' Office, Westburn Centre, Foresterhill, Aberdeen

${ }^{*}$ Correspondence to: Elizabeth Russell, Department of Public Health, University of Aberdeen, Polwarth Building, Foresterhill, Aberdeen AB25 2ZD

Email:e.m.russell@abdn.ac.uk practice has risen in the past decade, their whole time equivalence (wte) is unknown. ${ }^{1}$ The DPD information differs from that held by the General Dental Council in the form of the Dentists Register. The Register identifies individuals with addresses, but gives no indication of where - or indeed whether - that individual is currently undertaking dental practice in Scotland. Previous work ${ }^{2,3,4}$ had found that for recent dental graduates the issues of pressure at work, postgraduate training, and health and career pathways were important determinants of retention within the profession and of future career paths. In addition, since the proportion of the workforce that is female is increasing (nearly half of UK graduates in 1998), the question of flexible working is now crucial. ${ }^{5}$ Other recent publications had described perceived sources of occupational stress in general dental practitioners only, 6,7 and had identified changes in contractual arrangements and uncertainty about the future organisation of dental care provision as potential new stressors. We were keen to relate this concern to dentists' career plans in both general and community dental practice.

The aims of this study therefore were:

- To identify the real available workforce in general dental practice.

- To describe the career and retirement plans of GDPs and CDPs.

- To describe the perceived motivation and job satisfaction of GDPs and CDPs.

- To identify dentists with Scottish home addresses in the Dentists Register who are not working in Scotland, but who may have a need for flexible training and advice about work.

\section{MATERIALS AND METHODS}

Postal self-completion, semi-structured questionnaires were sent to all GDPs and CDPs identified from the Dental Practice Division as being in practice in Scotland. The content of the questionnaires (comparable but slightly different for the two branches of dentistry to reflect differences in their employment status) was derived from literature ${ }^{2-4}$ and from interviews with members of the project's professional steering group. All questionnaires were piloted before being finalised. They were accompanied by a pre-paid addressed envelope and letter of invitation to respond, detailing the purposes and potential uses of the information. It was signed by the principal investigator (ER). Two reminder letters and questionnaires were sent to those who did not respond to the initial invitation to participate. Those who did not wish to respond were invited to return a blank questionnaire in the final reminder. The questionnaires were 
not named but were coded so that reminders could be sent and respondents could be followed up at a later date. However, confidentiality of individual unnamed responses was guaranteed through strictly controlled filing and access before aggregation.

The questions mainly combined tick-box options with space for comments. They addressed areas of personal demographics, current working patterns, training and $\mathrm{CPD}$, specialisation and skill mix within the practice, and job satisfaction including views on the remuneration system. The DPD list of practising dentists was also matched to the dentists on the Dentists Register who had Scottish home addresses. Those who were not on the DPD list were surveyed to find dentists from Scotland who were not working in dentistry. This second survey used a shortened questionnaire to determine reasons for not working, or other reasons for not receiving remuneration within the National Health Service in Scotland.

Analysis of the completed questionnaires was undertaken on SPSS version 10.0. Most responses were analysed by age and sex for significant differences, using Pearson's chi-square tests of significance. The free text or open-ended responses were coded by categories to create relatively homogeneous summary descriptors, usually of reasons for particular opinions or actions.

Only a selection of the findings is presented here. The full report is available from the Scottish Council for Postgraduate Medical and Dental Education, (now NHS Education for Scotland) who published it in $2001 .^{8}$ The educational issues will be published separately. ${ }^{9}$

\section{RESULTS}

\section{General dental practitioners (GDPs)}

The analysis is based on 1,335 dentists. Of 1,357 responses to 1,917 questionnaires 22, were duplicates or largely incomplete and were not used, giving a usable response rate of 70.0\%. Two-thirds (66\%) of the $1,335 \mathrm{GDP}$ respondents were male, and the median age was 38 years; $56 \%$ were principals and $36 \%$ associates.

The response rate did not differ between males and females. The youngest age group had a significantly higher response rate (>90\%) but there was no significant difference in response among the older age groups. The distribution of age and sex was not significantly different from that of the general dental practitioners on the Dental Practice Division list for 1999.

\section{GDPs' working time}

Because 'part-time' can be variably interpreted, respondents were asked how many hours they worked per week on different activities. The majority of GDPs (62\%) worked between 30 and 47 hours per week on NHS dentistry (mode 35 hours, median 34 hours). The 1,313 respondents to this question worked a whole time equivalent (wte) of 1,024 GDPs in NHS clinical work, or 78\% of their time. An additional 104 wte was spent in administration to a total of 1,128 dentists, or $86 \%$ of the 1,313. A quarter of GDPs did no administration.

Half of female GDPs did less than 30 hours NHS clinical work per week compared with $27 \%$ of males, while just over a third of both practice owners and associates worked less than 30 hours per week. These figures show much less difference between genders and by ownership than does the BMRB survey, which found that less than $10 \%$ of male GDPs worked 'part-time' and only $12 \%$ of practice owners. ${ }^{10}$

Nearly half (47\%) reported that they did no private work, and those who did spent a median of only 3 hours per week on it. The time recorded on private practice was equivalent to 72 wte dentists or $5 \%$ of the 1,313; this included 35 respondents who were doing more than 30 hours per week in private or independent dentistry.

The total of NHS and private clinical work means that $83 \%$ of the available dentists' time is spent on direct clinical work, and 91\% when administration is included. The remainder of their time was spent on hospital attachments, CPD and in other aspects of dentistry such as community clinics or salaried work (Table 1).

\section{Table 1 Work patterns of dentist in primary care in Scotland}

General \% (actual) $n=1335 \quad$ Community \% (actual) $n=187$

\begin{tabular}{lcc}
\hline Sex & $66(882)$ & \\
Male & $33(445)$ & $34(63)$ \\
Female & $+(8)$ & $66(124)$ \\
Not answered & & 0 \\
& & \\
Age of respondent & & \\
$<30$ & $21(280)$ & $8(14)$ \\
$30-39$ & $33(439)$ & $28(54)$ \\
$40-49$ & $27(360)$ & $34(67)$ \\
$50-59$ & $16(212)$ & $24(46)$ \\
$60-64$ & $2(23)$ & $6(12)$ \\
$65+$ & $+(3)$ & 0 \\
Not answered & $1(14)$ & 0 \\
mean & 39.02 & 43.41 \\
median & 38 & 42 \\
range & $23-68$ & $23-64$
\end{tabular}

Hours per week work in clinical NHS dentistry

$\begin{array}{llc}\text { None } & 2(28) & 5(10) \\ \text { Less than 16 hours } & 12(166) & 10(19) \\ 16 \text { to } 29 \text { hours } & 20(271) & 33(62) \\ 30 \text { to } 47 \text { hours } & 62(832) & 51(95) \\ 48 \text { or more hours } & 1(16) & +(1) \\ \text { mean } & 29.2 & 27.1 \\ \text { median } & 34 & 30 \\ \text { range } & 0-60 & 0-49\end{array}$

Hours per week of administrative work in NHS dentistry

$\begin{array}{lcc}\text { None } & 25(330) & 81(151) \\ \text { Less than } 5 \text { hours } & 50(662) & 3(6) \\ 5 \text { to } 10 \text { hours } & 22(292) & 4(8) \\ 11 \text { to } 15 \text { hours } & 2(29) & 4(8) \\ 16 \text { or more hours } & 1(9) & 7(13) \\ \text { mean } & 3.0 & 2.7 \\ \text { median } & 2 & 0 \\ \text { range } & 0-26 & 0-40\end{array}$

Hours per week of private/ independent work in dentistry

None $\quad 47(628) \quad 100(187)$

Less than 16 hours $\quad 41(542) \quad 100(187)$

16 to 29 hours $\quad 8(112)$

30 or more hours

mean 2.1

median 0

$0-40$

aRecoded age as $1=<30,2=30-39,3=40-49,4=50+$ for cross tabulations and chi-square tests. Base: All general dental practitioner respondents $(1,335)$

Base: All community dental practitioner respondents (187)

\section{GDPs' job satisfaction and career plans}

Two-thirds (64\%) would still choose dentistry as a career and $78 \%$ enjoyed their work. This was most likely in those aged less than 30 . Those who would not return to dentistry did not identify any single reason for their view.

Job satisfaction was attributed to a wide range of the factors that were offered as options. As well as helping people and improving oral health, daily motivation was derived from the flexibility of the working hours, especially for women (Table 2). However, 70\% of GDPs were discouraged on a daily basis by a wide range of factors relating to both the job and the patients. Time pressure was the most common factor quoted (described as the 'treadmill effect'), followed by poor NHS fees, broken appointments, and then patients variously categorised as with high expectations, disinterested (especially teenagers), or difficult (Table 3).

Four per cent of GDPs had changed discipline within dentistry, or to another profession. The same proportion currently planned to do so but a further 30\% indicated that they might contemplate it later. Only 6\% planned to change to private dentistry and only $2 \%$ to a salaried post but $18 \%$ indicated they might at a later stage consider a salaried post (Table 4). 


\begin{tabular}{|c|c|c|}
\hline What gives job satisfaction & $\begin{array}{c}\text { General \% (actual) } \\
n=1335\end{array}$ & $\begin{array}{c}\text { Community \% (actual) } \\
n=187\end{array}$ \\
\hline \multicolumn{3}{|l|}{ Income } \\
\hline Agree & $69(907)$ & $53(96)$ \\
\hline \multicolumn{3}{|l|}{ Patient management } \\
\hline \multirow{2}{*}{\multicolumn{3}{|c|}{ Raising patients' oral health / quality of life }} \\
\hline & & \\
\hline \multicolumn{3}{|l|}{ Improving patients appearance } \\
\hline Agree & $93(1232)$ & $73(132)$ \\
\hline \multicolumn{3}{|l|}{ Job variety } \\
\hline Agree & $62(822)$ & $80(145)$ \\
\hline
\end{tabular}

\begin{tabular}{lcc} 
Table 3 Reasons for demotivation on a daily basis & \\
\hline Why feel demotivated & General \% $\mathrm{n}=\mathbf{9 2 9}$ & Community $\% \mathrm{n}=119$ \\
\hline The job & 52 & 50 \\
Patients & 54 & 23 \\
Staff $/$ practice & 10 & 27 \\
NHS & 13 & 7 \\
Other & 13 & 24 \\
Not answered & 3 & 10
\end{tabular}

Base: All general dental practitioners who feel demotivated on a daily basis (929) Base: All community dentists who feel demotivated on a daily basis (119) (Multiple answers were possible)

Two thirds of GDPs planned to retire early, at a median age of 55 , with half of this group planning to reduce their clinical hours in the years before retirement. In addition, a quarter of all GDPs planned to work part-time. The main reason given for early retirement was to be able to have leisure and enjoy retirement while fit $(70 \%)$. However, the increasingly poor NHS piecework rate was also a factor (46\%), as were patient expectations of treatment at uneconomic rates (40\%). Stress was identified by a third of GDPs as a reason for early retirement. Nonetheless, 74\% of those who planned to retire early might be induced to stay on by their financial commitments, by an NHS system that values quality not quantity, and by increased payment rates (Table 5).

Eleven per cent of GDPs had taken maternity/paternity leave (2\% of males and $30 \%$ of females), and $9 \%$ of the total workforce were planning to do so. The mean planned time off was six months for females and one month for males, but two-thirds also wished to reduce their clinical hours thereafter.

\section{Community dental practitioners (CDPs)}

There was a 75\% response rate. In exact contrast to the GDPs, twothirds of the 187 respondents were female, and the median age was 42 years; 69\% were community dental officers, 13\% senior dental officers and 8\% were in management either full or part-time.

\section{CDPs' working time}

Half the CDPs worked 30-47 hours per week on clinical NHS work (mean 27, median 30 hours); 43\% worked less than 30 hours. Overall, a mean of 2.7 hours was spent on administration, although this was concentrated in only $19 \%$ of the CDPs. None reported doing private work (Table 1).

\section{CDPs' job satisfaction and career plans}

CDPs chose their work because it was interesting and fitted in with family and personal life. Flexibility of working hours mattered to a quarter of the female CDPs. Seventy per cent would choose to do dentistry again; those who would not, identified a wide range of factors in the job as the reasons, but very few in the patients.

Job satisfaction was derived from a range of factors, of which improving patients' oral health and quality of life was uppermost

\begin{tabular}{|c|c|c|}
\hline & $\begin{array}{c}\text { General \% (actual) } \\
n=1,335\end{array}$ & $\begin{array}{c}\text { Community \% (actual) } \\
n=187\end{array}$ \\
\hline \multicolumn{3}{|l|}{ Have done: } \\
\hline Taken maternity / paternity leave & $12(147)$ & $23(41)$ \\
\hline Worked part-time & $15(195)$ & $27(50)$ \\
\hline \multicolumn{3}{|l|}{ Plan to: } \\
\hline Retire early & $66(885)$ & $34(63)$ \\
\hline Take maternity / paternity leave & $9(113)$ & $5(9)$ \\
\hline Change to another branch of dentistry & $3(35)$ & $2(4)$ \\
\hline Change to another profession & $1(18)$ & $2(4)$ \\
\hline Work part-time & $23(301)$ & $5(9)$ \\
\hline \multicolumn{3}{|l|}{ Do not plan to: } \\
\hline Retire early & $32(414)$ & $64(116)$ \\
\hline Take maternity / paternity leave & 79 (999) & $72(130)$ \\
\hline Change to another branch of dentistry & $76(975)$ & $80(145)$ \\
\hline Change to another profession & $86(1118)$ & $87(157)$ \\
\hline Work part-time & $61(788)$ & $68(125)$ \\
\hline Career plans of female dentists & $n=448$ & $n=124$ \\
\hline \multicolumn{3}{|l|}{ Maternity leave: } \\
\hline Taken & $30(134)$ & $34(42)$ \\
\hline Planned & $21(94)$ & $5(6)$ \\
\hline Work part time thereafter & $79(354)$ & $60(74)$ \\
\hline \multicolumn{3}{|l|}{ Work part time: } \\
\hline done & 35 (157) & $39(40)$ \\
\hline planned & $25(112)$ & $4(5)$ \\
\hline \multicolumn{3}{|l|}{ Retire early: } \\
\hline Planned & $67(300)$ & $28(35)$ \\
\hline Also reduce hours & $46(206)$ & $16(20)$ \\
\hline \multicolumn{3}{|c|}{$\begin{array}{l}\text { Base: All general dental practitioner respondents }(1,335) \\
\text { Base: All community dental practitioner respondents (187) } \\
\text { (Multiple answers possible) }\end{array}$} \\
\hline
\end{tabular}

(85\%). Job variety (78\%) was also important. Clinical work with children was the most enjoyed component of their work, and the explicit reason that many had gone into community dentistry (Table 2). Despite this, two thirds of community dentists were dispirited on a daily basis by their jobs, within which the heavy workload and poor management were specified. They were also asked if they felt underemployed, and 81\% replied yes. However, the additional comments that they volunteered suggested that it was their skill rather than their time that was not being adequately used (Table 3).

The median planned age of retirement was 57, but only $16 \%$ planned to reduce their clinical hours before retirement. As with GDPs, CDPs' most common reason for retiring early was to have time to enjoy retirement (66\%). Stress was specifically identified by a quarter.

Of those CDPs planning to retire early (63), more than $40 \%$ would not be persuaded to delay their planned date, but a fifth might stay if they had a salaried position with negotiable hours of work (Table 5).

A fifth of the CDPs had taken maternity leave and more planned to do so. The average leave period was 10 months, and more than half indicated that they had or would reduce their clinical hours following such leave (Table 4).

\section{Comparisons of GDPs and CDPs}

There are more similarities than differences between GDPs and CDPs but also some largely expected differences. The sex ratio of males to females is reversed in the two disciplines, 2:1 among GDPs and the converse in CDPs. The percentage of GDPs under the age of 30 is nearly three times that within CDPs $(21 \%$ compared with $8 \%$ ), and half of this group of GDPs is female. 


\begin{tabular}{|c|c|c|}
\hline Reasons for retiring early & $\begin{array}{l}\text { General \% } \\
\text { (actual) } n=889\end{array}$ & $\begin{array}{l}\text { Community \% } \\
\text { (actual) } n=63\end{array}$ \\
\hline To be able to enjoy retirement & $70(620)$ & $65(45)$ \\
\hline Health problems & $16(142)$ & $32(22)$ \\
\hline Stress & $36(320)$ & $28(19)$ \\
\hline Demanding/ negative attitudes of patients & $35(309)$ & $20(14)$ \\
\hline Heavy workload & $35(308)$ & $13(9)$ \\
\hline Poor NHS piece work rate & $46(405)$ & $4(3)$ \\
\hline Patient expectation of treatment at uneconomic rates & $40(359)$ & $6(4)$ \\
\hline Lack of enjoyment of work & $24(211)$ & $29(20)$ \\
\hline Isolation in a dental surgery & $18(157)$ & $19(13)$ \\
\hline Lack of job variety & $10(91)$ & $15(10)$ \\
\hline Not answered & $23(201)$ & $22(15)$ \\
\hline \multicolumn{3}{|c|}{$\begin{array}{l}\text { NB Non responses, 'yes, if was allowed' responses, maybe responses, and don't know } \\
\text { responses were excluded from the cross tabulation and chi-square calculation } \\
\text { Base: All general dental practitioner respondents who plan to retire early (889) } \\
\text { Base: All community dental practitioner respondents who plan to retire early (63) } \\
\text { (Multiple answers possible) }\end{array}$} \\
\hline
\end{tabular}

Forty-three per cent of CDPs do less than 30 hours of clinical work per week compared with 32\% of GDPs. The pattern of administrative work is also different, being concentrated in senior staff in the community dental service but undertaken by three-quarters of GDPs.

Apart from the business side of general dental practice the sources of job satisfaction - and dissatisfaction - were similar. However, GDPs were more likely to attribute daily demotivation to factors in their patients, such as broken appointments and lack of interest in oral health. Nearly twice the percentage of GDPs planned to retire early or work part-time, but more of them might be persuaded to stay on. However, more CDPs stated positively that they would not retire early, nor plan to reduce their working hours before retirement. The planned age of retirement was similar as was the main reason for it, namely the wish to enjoy retirement while still able to do so.

Female GDPs were more likely than female CDPs to be planning maternity leave; this might be because they were on average younger. However, they were also more likely to be planning to work part-time thereafter. Female GDPs were much more likely than female CDPs to be planning to work part-time and to take early retirement.

\section{Dentists who may be on a career break}

Dentists who are not currently on the Dentists Register are extremely difficult to identify. There were 709 dentists with a Scottish address on the Dentists Register but who were not on the DPD list; they were sent a short questionnaire to identify their current location and whether they were working as a dentist. of the 361 (51\%) who replied, a fifth were still working, deceased or not traceable through their register address. Of the rest, the majority had missing or wrong General Dental Council (GDC) numbers and were eliminated when these were corrected at DPD.

By this method, only 18 dentists identified themselves as being on a career break; ten of them definitely planned to return to work, six were uncertain and two were planning to change career. A third of the career break group had cancelled their GDC registration after the GDC data was extracted in February 2000.

\section{DISCUSSION}

\section{The NHS available workforce}

One of the main areas of concern that this survey planned to explore was that of the current available workforce and its future plans. Clearly there are differences in delivery of care across the United Kingdom; Buck and Newton ${ }^{11}$ reported that about 5\% of patients on GDPs' books were treated privately in Scotland compared with 50\% in the South East and South West of England. This is the first time that the wte of GDPs has been quantified, and the self-reported figure of $91 \%$ is higher than the $80 \%$ quoted by the BDA in its evidence to the review body $2000 .{ }^{12}$ However, the working patterns of the $30 \%$ who did not respond to this questionnaire is not known, and it is possible that a higher proportion of them were solely in private practice than the 35 individuals who did respond.

The issue, however, is whether this percentage will increase. There is also concern that the switch to at least equal numbers of women in the workforce will diminish the proportion of skilled time available to the population who need dental care. The data from this study suggest that the women dentists who have had their children have indeed taken maternity leave and been more likely to work part-time thereafter. However it is not clear whether the next generation of women will do likewise, and it is crucial that the younger cohort of dentists of both sexes is followed up to identify their work plans and actions. The findings of this survey suggests that the loss from early retirement - mainly but not wholly planned for the mid and late 50s - may be just as great and is likely to increase unless some of the dispiriting factors in primary care dentistry are removed. These are many, but above all is the concern that quality has given way to quantity and lack of incentives for professional development. It is highly relevant that a significant number, of GDPs in particular, indicated their willingness to continue beyond their planned retirement date if working conditions were changed to meet these concerns. There may be lessons from general medical practice, since government responded positively in the 1960s to a mass exodus from primary care because of the lack of professional pride and incentives for continuing professional development. However, a recent survey of 1,974 UK medical graduates (median age 48) found only 35\% definitely or probably going to stay to retirement age, and the reasons given were very similar to those given in this dental study. Again, women doctors were slightly more likely than men to be planning to continue working. ${ }^{13}$

In view of the increasing female workforce it is especially interesting to note the contrast between female GDPs and CDPs in their long term career plans. Female GDPs were much more likely than female CDPs to be planning to work part-time and to take early retirement. Clearly the current general practice system with its strong emphasis on running an effective business as well as delivering oral healthcare has historically not enticed women to work full time delivering clinical care. Is it, as has been suggested, a lack of skill, training or interest in business matters ${ }^{14}$ Or do women prefer to do a different type of dentistry? Is the current piecework system itself a demotivating factor? Anecdotal evidence from vocational trainers (personal communication) and results of the National Survey of Vocational Dental Practitioners $2001^{15}$ suggests that this disenchantment with the current system is prevalent in both sexes in the recently qualified workforce. This problem needs to be investigated and effective solutions sought urgently. A realistic prevention-based national oral health strategy may well be the way ahead as a more cost-effective and professionally satisfying strategy, but it requires an aware and participative public.

The solutions for the 21st century may have to be even more flexible and imaginative to cope with society's changing expectations about the role of work. For example, is it feasible to have an effective, affordable core dental service provided by practitioners being paid a salary for perhaps three days per week? Those wishing to work longer hours could elect to enhance their earnings by providing non-NHS treatment or pursuing other areas of dental interest eg clinical attachments in secondary dental care, further degrees or for those with other commitments, simply to have more free time. Could this be a solution with sufficient flexibility to appeal to, and retain in the workforce, those in the dental profession who might otherwise be lost, whilst at the same time allowing full time practitioners a greater degree of flexibility in their careers? 
The data collection and main analyses for this project were carried out by Tracy Harrold, without whom the study would not have been completed. We are also very grateful to all the dentists in primary care in Scotland who completed the lengthy questionnaire and volunteered so many additional comments. The study was funded by the former Scottish Council for Postgraduate Medical and Dental Education, (now NHS Education for Scotland) to whom we express our thanks.

1. Scottish Health Statistics, 1998, ISD Scotland (Medical and Dental Manpower Census; General Medical Practitioner Database, ISD (M) 5, 6 and 31.) Dental Practice Division, 1999

2. Baldwin P J, Dodd M, Rennie J S. Young dentists - work, wealth, health and happiness. BrDent J 1999, 186:30-36.

3. Baldwin P J, Dodd M, Rennie J S. Careers and patterns of work of Scottish dental graduates: 1991 and 1994. Br Dent J 1998, 185:238-243.

4. Baldwin PJ, Dodd M, Rennie J S. Postgraduate dental education and the 'new' graduate. BrDent J 1998, 185: 591-594.

5. Scottish Executive Health Department. Workforce planning for dentistry in Scotland, a strategic review. Interim report and recommendations. September 2000.

6. Wilson R F, Coward PY, Capewell J, Laidler T L, Rigby AC, Shaw T J. Perceived sources of stress in general dental practitioners. Br Dent J 1998; 184: 499-502.

7. Humphris $\mathrm{G} M$, Cooper C L. New stressors for GDPs in the past ten years: a qualitative study. Br Dent J 1998; 185: 404-406.

8. Russell E, Harrold T, Watson S. A Scottish survey of general and community dental practitioners 2000. Scottish Council for Medical and Dental Postgraduate Education, 2001.

9. Leggate $M$, Russell E. Attitudes and trends of primary care dentists to continuing professional development. BrDent JIn press.

10. Kitchen S, Ashworth J. Survey of GDPs' workloads: Final Report. Office of Manpower Economics BMRB/JA/SK/1154-1161, October 2000.

11. Buck D, Newton J T. The privatisation of NHS dentistry? A national snapshot of general dental practitioners. BrDent J 2001 190: 115-118.

12. British Dental Association. Evidence to the House of Commons Health Committee on Future NHSStaffing Requirements. BDA October 1998.

13. Davidson J M, Lambert T W, Parkhouse J, Evans J, Goldacre M J. Retirement intentions of doctors who qualified in the United Kingdom in 1974: postal questionnaire survey. J Public Health Med 2001, 32; 323-334.

14. Seward M, Better Opportunities for Women Dentists. Full text available from http://www.doh.gov.uk/betteropportunitiesforwomendentists/ See Executive Summary, page xii.

15. Lane D A, Bennet A W. Vocational dental practitioners'survey. April 2001 http://www.vtsurvey.com/results.htm.

\section{APPENDIX}

Several cautions should be noted about the numbers, percentages and statistical calculations presented in this report. First, a sizeable proportion of dentists had more than one job relevant to the survey, such as being a community dentist working one session in general practice, or being salaried for only part of their working time. This led to some difficulties in ensuring that responses were included in the most appropriate group for analysis, and to some analyses having different inclusions for apparently the same nominal group. Second, respondents did not complete every question in the questionnaire, so the totals may vary for each question and non-respondents were always excluded in calculations for significant differences. Moreover, the numbers in tables about the same data may vary depending on whether or not a cross tabulation or statistical test was performed; this is because of the way that the analytical package handles responses that do not fit the main categories. Third, because of the large numbers of responses, the analysis yielded many statistically significant differences by sex or by age. Unless specifically stated to be not significant, no differences are reported unless they are significant at least at the 5\% level, expressed as $\mathrm{p}<0.05$. This means that there is only a $5 \%$ probability that the differences could have happened by chance. However, because of the large numbers of analyses it is inevitable that some of the apparently significantly different findings themselves happened by chance. We have therefore reported differences in the text only when they also made sense by observation of the data. 